\title{
Urgences
}

\section{Marc fixait...}

\section{Marie Desrosiers}

Numéro 13, mars 1986

\section{Éclats d'atelier}

URI : https://id.erudit.org/iderudit/025208ar

DOI : https://doi.org/10.7202/025208ar

Aller au sommaire du numéro

\section{Éditeur(s)}

Urgences

\section{ISSN}

0226-9554 (imprimé)

1927-3924 (numérique)

Découvrir la revue

\section{Citer ce document}

Desrosiers, M. (1986). Marc fixait... Urgences, (13), 27-27.

https://doi.org/10.7202/025208ar

Ce document est protégé par la loi sur le droit d'auteur. L'utilisation des services d'Érudit (y compris la reproduction) est assujettie à sa politique d'utilisation que vous pouvez consulter en ligne.

https://apropos.erudit.org/fr/usagers/politique-dutilisation/ 


\section{Marie Desrosiers}

Marc fixait les trois oranges ridées. Le parfum des rosiers se confondait au rosé du camembert, à côté d'un bourgogne entamé et d'un verre d'eau. Briser l'écran.

II se cambre sur son coussin marron, il sourit. II secoue les dés dans sa poche en rotant. Deux des pattes de sa chaise d'osier sont à quelques pouces du sol. II zigouillerait cette mouche au fer ou à l'épée sans bégayer.

Il avait eu ce projet de jongler avec trois fruits. Mais il faudrait pratiquer de midi à quatorze heures. Pas aujourd'hui. Allait-il relire M.D. de Yann Andréa, qu'il traînait dans sa sacoche, l'air de rien. Une lente désintoxication, comme une désintégration contrôlée. À quelle adresse?

Il louche sur la coupe de vin, les reflets dorés transpercent son iris. Y a-t-on fondu un grenat, qu'il hypnotise ce rouge? II devait partir à Montréal comme c'était prévu. Coup de téléphone imprévu. Les possibilités se multiplient. Et ce cours en créativité. Et la tête et le coeur et l'instinct, et le travail et l'argent et les loisirs. Tous ces mots virevoltaient et retombaient on ne sait où, mais au sens figuré. Virements, revirements, la splendeur du Cap à l'Orignal. Silence. Cet autre retour en chantant, sans parler de son père et de sa mère. Et pendant tout ce temps vouloir tenir cela en équilibre sur quelque vingt lignes. En quelle clé? Et le cinéma! Trois gros plans des lèvres du héros, dont deux où il recrache un grain de tabac, en jetant les dés. Autre plan.

Sa main dépose une feuille de menthe dans le verre d'eau, pour la couleur et le parfum. L'autre se dirige vers une des trois oranges qui n'ont pas bougé. 